\begin{tabular}{|l|l|l||}
\hline \multicolumn{2}{|c|}{ PublisherInfo } \\
\hline \hline PublisherName & $:$ & BioMed Central \\
\hline \hline PublisherLocation & $:$ & London \\
\hline \hline PublisherImprintName & $:$ & BioMed Central \\
\hline \hline
\end{tabular}

\title{
Barbiturate coma for vasospasm following SAH
}

\begin{tabular}{|l|l|l||}
\hline \multicolumn{2}{|c||}{ ArticleInfo } \\
\hline \hline ArticleID & $:$ & 4112 \\
\hline \hline ArticleDOI & $:$ & $10.1186 /$ ccf-1999-334 \\
\hline \hline ArticleCitationID & $:$ & 334 \\
\hline \hline ArticleSequenceNumber & $:$ & 49 \\
\hline \hline ArticleCategory & $:$ & Paper Report \\
\hline \hline ArticleFirstPage & $:$ & 1 \\
\hline \hline ArticleLastPage & $:$ & 4 \\
\hline \hline & & RegistrationDate : 1999-5-19 \\
\hline ArticleHistory & $:$ & OnlineDate \\
\hline \hline ArticleCopyright & $:$ & Current Science Ltd1999-5-19 \\
\hline \hline ArticleGrants & $:$ & \\
\hline \hline ArticleContext & $:$ & 130541111 \\
\hline \hline
\end{tabular}




\section{Keywords}

Barbiturate, papaverine, subarachnoid haemorrhage, vasospasm

\section{Comments}

The protective effects of burst suppression barbiturate therapy has beenproven in animal models of cerebral ischaemia but unfortunately dismalresults have been shown in patients presumably because irreversible damagehas occurred prior to therapy commencing. This study in a small number ofpatients shows optimism possibly because identification of vasospasm andtherefore potential ischaemia was prompt allowing early initiation oftreatment. However much larger studies are required prior to embarking on atreatment which requires complicated intensive care supportive therapy dueto potential serious adverse events.

\section{Introduction}

Cerebral artery vasospasm accounts for nearly a quarter of themortality following subarachnoid haemorrhage (SAH). Treatments includecalcium antagonists, triple $\mathrm{H}$ therapy and angioplasty (chemical andphysical) if available, although significant morbidity and mortality remain.Experimentally EEG burst suppression induced by barbiturates protectsagainst cerebral ischaemia. Unfortunately studies in 1980 utilising thistechnique in patients with ischaemia produced by vasospasm produced grimresults and further investigation was halted.

\section{Aims}

To investigate the role of barbiturate coma in the management ofvasospasm resistant to other treatments including angioplasty.

\section{Methods}


Patients following urgent aneurysmal repair are managed accordingto a previously published protocol on the intensive care unit (ICU). Essentially vasospasmdetected electively by angiography at day 5-7 following SAH (maximum risk)or earlier if clinically indicated is treated with papaverine injected intothe appropriate artery. Arterial systolic pressure is increased to $160-180 \mathrm{mmHg}$ and papaverine angioplasty is repeated each day until vasospasmresolves. Balloon angioplasty is attempted if vasospasm persists and then ifthis fails barbiturate induced burst suppression is implemented.Eleven patients who had attained 6 months of follow up were managed withbarbiturate induced burst suppression. The Glasgow Outcome Scale was used torate neurological outcome and mortality was compared to predicted APACHE IImortality, and previous studies utilising nimodipine to treat patients withischaemic deficit secondary to vasospasm.

\section{Results}

One hundred and sixty-four consecutive patients treated according to protocol werereviewed. Eleven patients with symptomatic vasospasm (varying from mild cognitiveto severe motor deficits and decreased conscious level) received barbituratecoma therapy where chemical angioplasty had failed on a number ofoccasions. Thiopentone $10 \mathrm{mg} / \mathrm{kg}$ was infused intravenously over $20 \mathrm{~min}$ andbarbiturate coma was maintained with an infusion rate adjusted to maintain aburst suppression EEG pattern. Intended duration of barbiturate therapy was 3 days but three patients required earlier discontinuation because of infectiouscomplications and two patients received longer infusions because of persistentangiography proven vasospasm. Following termination of barbiturate infusionmedian times for return of pupillary light reflex and motor response topainful stimuli were 18.5 and $80 \mathrm{~h}$, respectively.Predicted mortality from APACHE II was 31\% but all 11 patients survived tohospital discharge. Literature search revealed survival rates of $19 \%$ fromprevious reports of patients receiving barbiturate therapy for vasospasm -none of these survivors made a good neurological recovery.Ten of 11 patients $(91 \%)$ had a good neurological outcome when rated by theGlasgow Outcome Scale at 6 months following discharge. This compared to $51 \%$ for historical controls in patients receiving nimodipine for delayedischaemic deficit from vasospasm.

\section{Discussion}

Calcium antagonists may improve prognosis for vasospasmfollowing SAH, but evidence is limited for triple $\mathrm{H}$ therapy and angioplastyhas yet to be validated in controlled trials. This study suggests that thesmall number of patients with vasospasm despite angioplasty may benefit frombarbiturate coma. Protective effects are thought to be due to a reduction incerebral oxygen consumption and intracranial pressure, and via free radicaland fatty acid metabolism. However immune and cardiovascular depression andlengthy artificial ventilation and intensive care therapy are majordrawbacks of this therapy. Previous studies utilising barbiturate comatherapy have shown dismal results and the authors question whether improvedintensive care therapy, earlier implementation of therapy or chance explaintheir very encouraging results which are comparable with present therapiesfor vasospasm following SAH. 


\section{References}

1. Finfer SR, Ferch R, Morgan MK: Barbiturate coma for severe, refractory vasospasm following subarachnoid haemorrhage. Intensive Care Med. 1999, 25: 406-409.

This PDF file was created after publication. 